Revista Eletrônica de Direito Processual - REDP.

Rio de Janeiro. Ano 11. Volume 18. Número 2. Maio a Agosto de 2017

Periódico Quadrimestral da Pós-Graduação Stricto Sensu em Direito Processual da UERJ

Patrono: José Carlos Barbosa Moreira. ISSN 1982-7636. pp. 327-346

www.redp.uerj.br

\title{
IMPLICANCIAS DE UNA INDEBIDA APLICACIÓN DEL NUEVO PROCESO INMEDIATO COMO CONSECUENCIA DE UNA ERRADA APRECIACIÓN DE LA \\ FLAGRANCIA DELICTIVA. A PROPÓSITO DE LA CASACIÓN N. 804-2016 SULLANA ${ }^{1}$
}

IMPLICATIONS OF AN UNDUE APLICATION OF THE NEW IMmEDIATE

PROCEDURE AS A CONSEQUENCE OF A WRONG APRECIATION OF FLAGRANT: REGARDING THE “CASACIÓN NUMBER 804-2016 SULLANA”

Jorge Isaac Torres Manrique

Consultor Jurídico. Abogado por la Universidad Católica de Santa María (Arequipa). Egresado de los Doctorados en Derecho y Administración, y de las Maestrías en Derecho Empresarial y Derecho Penal, por la Universidad Nacional Federico Villarreal (Lima). Columnista de la Asociación Civil El-terno.com (Perú). Miembro del Comité Científico Internacional del Instituto Jurídico Internacional de Torino (Italia). Miembro Asociado de E-Justicia Latinoamérica (Argentina). Experto en Derecho Empresarial y Administrativo, en Avalón, la Red de Expertos de España, Portugal y Latinoamérica (España). kimblellmen@outlook.com.

RESUMO: O autor trata de um caso em que um suspeito do crime de estupro de pessoa menor de sete anos de idade (art. 173, 1, do Código Penal peruano) foi preso "em flagrante", pela polícia, sem que estivessem presentes os requisitos legais do estado de flagrância. $\mathrm{O}$ suspeito foi denunciado pelo Ministério Público pelo referido crime e, em razão do suposto estado de flagrância, submetido ao denominado "processo imediato", um procedimento

\footnotetext{
${ }^{1}$ Artigo recebido em 18/05/2017, sob dispensa de revisão.
} 
Revista Eletrônica de Direito Processual - REDP.

Rio de Janeiro. Ano 11. Volume 18. Número 2. Maio a Agosto de 2017

Periódico Quadrimestral da Pós-Graduação Stricto Sensu em Direito Processual da UERJ

Patrono: José Carlos Barbosa Moreira. ISSN 1982-7636. pp. 327-346

www.redp.uerj.br

especial no qual as garantias fundamentais do processo penal são restringidas em prol da celeridade. $\mathrm{O}$ acusado foi condenado à prisão perpétua, em primeira instância. A condenação foi confirmada em segunda instância. $\mathrm{O}$ denunciado, então, recorreu à Suprema Corte peruana. Esta decidiu que, por não haver estado de flagrância, o acusado deveria ser submetido ao procedimento comum ao invés do "processo imediato". Entretanto, fundamentou a imediata soltura deste no excesso de prazo. O autor entende que embora a decisão da Suprema Corte esteja de acordo com a Constituição e a lei peruana, é ilegítima, já que a soltura do acusado deveria ter sido fundamentada na própria ausência do estado de flagrância. $\mathrm{O}$ autor propõe a capacitação e a conscientização em temas de administração da justiça, que seja dada prioridade à legitimidade das decisões judiciais em detrimento da celeridade e que o fundamento jurídico das decisões judiciais seja abordado também à luz da convencionalidade e da multidisciplinaridade.

PALAVRAS-CHAVE: processo imediato, flagrância delitiva, legitimidade das decisões judiciais, convencionalidade, multidisciplinaridade.

ABSTRACT: The author analyzes a case in which a suspect of the crime of rape of a person under seven years of age (article 173, 1, of the Peruvian Penal Code) was arrested "in flagrante delicto" by the police, without being present the legal requirements of the state of flagrance. The suspect was prosecuted by the Public Prosecution Office for the said crime and, because of the alleged flagrante delicto, submitted to the so-called "immediate process", a special procedure in which the fundamental guarantees of criminal proceedings are restricted in favor of speed. The accused was sentenced to life imprisonment at first instance. The conviction was upheld at second instance. The accused then appealed to the Peruvian Supreme Court. The court ruled that, as there was no flagrante delicto, the accused should be subject to the common procedure rather than the "immediate process". However, the court based his immediate release on the excess of the prison term. The author understands that although the decision of the Supreme Court is in accordance with the Constitution and the Peruvian law, it is illegitimate, since the release of the accused should have been based on the very absence of 
Revista Eletrônica de Direito Processual - REDP.

Rio de Janeiro. Ano 11. Volume 18. Número 2. Maio a Agosto de 2017

Periódico Quadrimestral da Pós-Graduação Stricto Sensu em Direito Processual da UERJ

Patrono: José Carlos Barbosa Moreira. ISSN 1982-7636. pp. 327-346

www.redp.uerj.br

flagrante delicto. The author proposes training and awareness raising on issues of administration of justice, that priority should be given to the legitimacy of judicial decisions to the detriment of speed, and that the legal basis of judicial decisions should also be addressed in the light of conventionality and multidisciplinarity.

KEYWORDS: immediate process, flagrant, legitimacy of judicial decisions, conventionality, multidisciplinarity.

SUMÁRIO: 1. A manera de introducción._- 2. Sobre el nuevo proceso inmediato.— 3. Acerca de la flagrancia delictiva. - 4. Acerca de la cuasi flagrancia.- 5. Resumen de la resolución sub examine.- 6. Análisis de la resolución in comento.- 7. Conclusiones.— 8. Sugerencias.- - 9. Referencias bibliográficas.

\section{A manera de introducción}

El delito de violación sexual de menor de edad comporta un manejo muy escrupuloso por parte de la administración de justicia penal. No obstante, ello se complica sobremanera cuando se le suma importantes instituciones jurídicas, como el proceso inmediato, la flagrancia delictiva, así como, la cuasi flagrancia. Ello, en tanto que eventualmente se termina vulnerando derechos fundamentales, basilarmente del denunciado.

En ese orden de pensamiento, para la presente entrega analizaremos la Resolución N. ${ }^{o}$ 842-2016-Sullana, expedida por la Primera Sala Penal Transitoria de la Corte Suprema de la República.

\section{Sobre el nuevo proceso inmediato}

El proceso inmediato es un proceso especial; y como apunta el profesor ARAYA VEGA, los procesos especiales “[...] son ágiles, expeditos; ya que al tratarse de asuntos de simple y 
Revista Eletrônica de Direito Processual - REDP.

Rio de Janeiro. Ano 11. Volume 18. Número 2. Maio a Agosto de 2017

Periódico Quadrimestral da Pós-Graduação Stricto Sensu em Direito Processual da UERJ

Patrono: José Carlos Barbosa Moreira. ISSN 1982-7636. pp. 327-346

www.redp.uerj.br

sencilla tramitación o resolución optó por la creación de un proceso simplificado que permita la descarga procesal, potenciar la disminución de la mora judicial y responder de manera pronta y oportuna a la justicia. Los procesos especiales se han establecido con la finalidad de juzgar de manera diferenciada a las personas que en virtud de condiciones especiales, modo de comisión del hecho o forma de resolución; se realizan de manera diferenciada a la ordinariamente establecida" ${ }^{2}$.

Por su parte, el artículo 446.1 del nuevo Código Procesal Penal, modificado por el artículo 2, del D. Leg. N. 1194 —que Regula el Proceso Inmediato en Casos de Flagrancia—, juridiza sobre los supuestos de aplicación de este proceso especial, señalando que: "1. El fiscal debe solicitar la incoación del proceso inmediato, bajo responsabilidad, cuando se presente alguno de los siguientes supuestos: a) El imputado ha sido sorprendido y detenido en flagrante delito, en cualquiera de los supuestos del artículo 259; b) El imputado ha confesado la comisión del delito, en los términos del artículo 160; o c) Los elementos de convicción acumulados durante las diligencias preliminares, y previo interrogatorio del imputado, sean evidentes".

\section{Acerca de la flagrancia delictiva}

Al respecto, el cuarto párrafo del fundamento jurídico $n .^{\circ} 2$, de la resolución del Tribunal Constitucional, Expediente N. ${ }^{\circ}$ 00354-2011-PHC/TC, enseña: “[...] la flagrancia es un instituto procesal con relevancia constitucional que debe entenderse como una evidencia del hecho delictuoso respecto de su autor. Así, la flagrancia se configurará cuando exista un conocimiento fundado, directo e inmediato del hecho punible que se viene realizando o que se acaba de realizar instantes antes, situación en la que, por su particular configuración, es necesaria la urgente intervención de la Policía para que actúe conforme a sus atribuciones. En

$2 \quad$ ARAya VEGA, Alfredo. "El nuevo proceso inmediato (Decreto 1194). Hacia un modelo de una justicia como servicio público de calidad con rostro humano", en Revista Informativa Ius Infraganti, año 1, n. ${ }^{\circ} 1$, Lima: marzo del 2016, pp. 07- 08. Recuperado de <bit.ly/1RCay0p>. 
Revista Eletrônica de Direito Processual - REDP.

Rio de Janeiro. Ano 11. Volume 18. Número 2. Maio a Agosto de 2017

Periódico Quadrimestral da Pós-Graduação Stricto Sensu em Direito Processual da UERJ

Patrono: José Carlos Barbosa Moreira. ISSN 1982-7636. pp. 327-346

www.redp.uerj.br

este sentido, lo que justifica la excepción al principio constitucional de la reserva judicial para privar de la libertad a una persona es la situación particular de la urgencia que, en el caso, concurriendo los requisitos de la inmediatez temporal e inmediatez personal de la flagrancia delictiva, comporta la necesaria intervención policial’”3.

Además, el fundamento jurídico n. ${ }^{\circ} 10$, de la jurisprudencia del Tribunal Constitucional, Expediente N. ${ }^{\circ}$ 05423-2008-HC/TC, agrega: “[...] la flagrancia debe entenderse como una evidencia del hecho delictuoso, por lo que solo se constituirá cuando exista un conocimiento fundado, directo e inmediato del hecho punible que se viene realizando o que se acaba de realizar. La mera existencia de sospechas o indicios no es un elemento suficiente para constituir la flagrancia""4.

\section{Acerca de la cuasi flagrancia}

En la cuasi flagrancia, denominada también como flagrancia presunta, se tiene como presupuestos: i) la inmediatez personal y temporal, pues, el autor en ese momento, lugar y circunstancias, se encuentra físicamente presente y acaba de perpetrar el hecho punible, ii) la percepción sensorial directa por la misma víctima, la autoridad policial o terceras personas, que el autor instantes antes acaba de perpetrar el hecho punible, iii) la persecución sin interrupción, perpetrado el delito, el autor huye, produciéndose una persecución, objetivamente percibida, por parte de la autoridad policial, por la víctima o por terceros que se encontraban en el lugar de los hechos, o que se sumaron a los perseguidores, y iv) la intervención del autor por el efectivo policial, o la aprehensión por la víctima o por terceros.

En ese sentido, amerita traer a colación el fundamento jurídico 3 de la jurisprudencia del Tribunal Constitucional, Expediente N. ${ }^{\text {o }}$ 1318-2000-HC/TC, que sostiene: “[...] no hubo

\footnotetext{
3 Tribunal ConstituCiOnal, Expediente N. ${ }^{\circ}$ 00354-2011-PHC/TC, Lima: 28 de marzo del 2011, f. j. n. ${ }^{\circ}$ 2.

4 Tribunal Constitucional, Expediente $N^{\circ}$ 05423-2008-HC/TC, Lima: 1 de junio del 2009, f. j. n. ${ }^{\circ} 10$.
} 
Revista Eletrônica de Direito Processual - REDP.

Rio de Janeiro. Ano 11. Volume 18. Número 2. Maio a Agosto de 2017

Periódico Quadrimestral da Pós-Graduação Stricto Sensu em Direito Processual da UERJ

Patrono: José Carlos Barbosa Moreira. ISSN 1982-7636. pp. 327-346

www.redp.uerj.br

comisión flagrante de delito, toda vez que la flagrancia supone la aprehensión del autor del hecho delictivo en el preciso momento de la comisión del mismo, más aun tratándose de delitos de comisión instantánea. Desde tal perspectiva, si de acuerdo a la sindicación del detenido, don Wilder Jara Vásquez, el favorecido le habría vendido la cantidad de un kilo cuatrocientos gramos de pasta básica de cocaína el día treinta de octubre de dos mil, en horas de la tarde, no puede considerarse detención en flagrancia cuando esta medida acontece en una fecha posterior, el día tres de noviembre a las $08 \mathrm{~h} 00 \mathrm{~min}$. Tampoco cabe justificar la presente detención dentro de la denominada figura de 'cuasiflagrancia' tal como lo sostiene la Sala Penal Corporativa de la Corte Superior de Justicia de El Santa, pues al margen de que ni siquiera es aplicable al caso subjudice, toda vez que la detención no se produjo en el momento inmediatamente seguido a la presunta comisión del hecho delictivo, además la Constitución Política del Estado no alude en absoluto al supuesto de 'cuasiflagrancia', por lo que no puede habilitarse subrepticiamente supuestos de detención no contemplados constitucionalmente, sencillamente, por aplicación del principio de interpretación según el cual, las normas establecen excepciones, y el artículo 2, inciso 24), literal 'f' que es regulatorio de las excepciones que restringen el derecho a la libertad individual, deben ser interpretadas restrictivamente"

\section{Resumen de la resolución sub examine}

Los hechos declarados probados en las sentencias de primera y segunda instancia, señalan basilarmente que en fecha 19 de enero del 2016, la menor agraviada de iniciales M.B.A.A., de 7 años de edad, se encontraba sola en su domicilio, cuando llegó el encausado Maximiliano Benites Rodríguez abusó sexualmente de la misma.

Con fecha 20 de enero del 2016 (22 horas de ocurrido el hecho), ante la sindicación de la madre de la agraviada y en presencia de esta última, la policía detuvo al imputado.

5 Tribunal ConstituCiOnal, Expediente $N .^{\circ} 1318-2000-H C / T C$, f. j. n. ${ }^{\circ} 3$. 
Revista Eletrônica de Direito Processual - REDP.

Rio de Janeiro. Ano 11. Volume 18. Número 2. Maio a Agosto de 2017

Periódico Quadrimestral da Pós-Graduação Stricto Sensu em Direito Processual da UERJ

Patrono: José Carlos Barbosa Moreira. ISSN 1982-7636. pp. 327-346

www.redp.uerj.br

Es de verse, que con fecha 20 de enero del 2016, el fiscal provincial de la Primera Fiscalía Provincial Penal Corporativa de Sullana, formula requerimiento de incoación de proceso inmediato.

En la referida fecha el mismo fue declarado procedente (por auto no impugnado). En dicha audiencia única, el fiscal solicitó mandato de prisión preventiva contra el citado encausado, lo que en igual fecha, el juez de la investigación preparatoria, declaró fundado, por un plazo de 5 meses.

Con fecha 15 de febrero del 2016, se condenó al acusado como autor del delito de violación sexual de menor de edad, a la pena de cadena perpetua. Fallo que con fecha 22 de junio del 2016, fue confirmado por sentencia de vista.

Con fecha 15 de julio del 2016, vía recurso de casación, la defensa del acusado introduce como motivos: la inobservancia de precepto constitucional y quebrantamiento de la garantía de motivación. Alegando que sed tramitó la causa en la vía inmediata como si se tratase de un supuesto de flagrancia delictiva, que no corresponde, afectándose el derecho de defensa del patrocinado. Ello, en tanto que la flagrancia no opera cuando es un tercero quien sindica al presunto autor, más aun si la detención ocurrió con posterioridad a los hechos, aunque antes de las 24 horas de su presunta comisión. Acotando que se interpretó extensivamente el artículo 259.3 del nuevo Código Procesal Penal y que la legalidad del procedimiento debió ser sostenida por el fiscal del juez. Además, que la sentencia de vista incurrió en motivación deficiente, porque no incorporó razones acerca de la ausencia de flagrancia delictiva y de la consiguiente arbitrariedad del arresto policial.

Con fecha 25 de noviembre del 2016, fue concedido el citado recurso, aunque en aplicación de la concepción de la "voluntad impugnativa", exclusivamente por la causal de 
Revista Eletrônica de Direito Processual - REDP.

Rio de Janeiro. Ano 11. Volume 18. Número 2. Maio a Agosto de 2017

Periódico Quadrimestral da Pós-Graduação Stricto Sensu em Direito Processual da UERJ

Patrono: José Carlos Barbosa Moreira. ISSN 1982-7636. pp. 327-346

www.redp.uerj.br

quebrantamiento de precepto procesal (art. 259.2 CPP), a fin de examinar la incoación del proceso inmediato y la corrección jurídica del procedimiento subsiguiente.

La resolución casatoria contempla además, que es verdad que el auto que aceptó el requerimiento de la fiscalía provincial, que dispuso que se siga la causa en la vía inmediata, no fue recurrido por el imputado. Sin embargo, no es posible sostener como regla jurídica pétrea que operó la preclusión de ese momento procesal y, por tanto, que tal declaración jurisdiccional ya se puede cuestionar en las demás etapas procesales.

También, que cuando se cuestiona sostenidamente en apelación y casación de las sentencias de mérito, la licitud de la concreta incoación del proceso inmediato, en el que se compromete una garantía constitucional, vinculada al debido proceso, como es la "interdicción de ser desviado de la jurisdicción determinada por la ley", a que hace mención el segundo párrafo del artículo 139.3 de la Constitución Política, no es de recibo aceptar dicho principio en el momento en que se advirtió su infracción. La convalidación y el saneamiento procesales cuando el vicio procesal configura una nulidad absoluta o insubsanable, que comprometen derechos y garantías fundamentales - artículo 150, literal d) del nuevo Código Procesal Penal - sino cuando únicamente no se observan las formalidades previstas en la ley para el desarrollo de un acto procesal — se circunscribe a los defectos no absolutos-.

Además, que el auto de incoación del proceso inmediato se declaró procedente porque se estimó que el imputado fue detenido en flagrancia delictiva.

Es de precisar, como dato esencial, el mérito del acta denominada de "Intervención Policial", acompañada por el recurrente en esta sede al que las sentencias de mérito han hecho mención. Allí se indica que cuando la menor agraviada, su madre y personal policial en una unidad policial se dirigían a la Fiscalía Provincial de Sullana, “[...] la madre de la menor logró visualizar el presunto autor del delito contra la libertad sexual (actos contra el pudor), quien se 
Revista Eletrônica de Direito Processual - REDP.

Rio de Janeiro. Ano 11. Volume 18. Número 2. Maio a Agosto de 2017

Periódico Quadrimestral da Pós-Graduação Stricto Sensu em Direito Processual da UERJ

Patrono: José Carlos Barbosa Moreira. ISSN 1982-7636. pp. 327-346

www.redp.uerj.br

desplazaba por la carretera Panamericana Norte $[\ldots]$ en un vehículo menor [...], siendo intervenido e identificado [...]".

En la sentencia de primera instancia, resumiendo la declaración de la madre de la agraviada, se anotó que "lo reconoce porque su hija le dio las características [...]; estaba vestido con ropa azul y en la moto roja al momento que ella lo observó”. Así mismo en la audiencia del juicio oral se ratifica la forma como se identificó, quien lo hizo y la detención policial consiguiente: estar en esta intervención, fue la declaración de la denunciante.

Sobre estas bases es que debe examinarse si correspondía o no el proceso inmediato y si en su actuación se vulneraron derechos básicos de carácter procesal del imputado, al punto que las sentencias de condena emitidas no pueden sostenerse por carácter de eficacia procesal.

Como es obvio, por tratarse de un proceso que restringe plazos procesales y elimina o reduce fases procesales - la flagrancia, como institución procesal, tiene u objetivo instrumental para facilitar la actuación de la autoridad policial o para instituir procedimientos simplificados y céleres - la interpretación de las normas que lo autorizan, por sus efectos, debe ser restrictiva, es decir, dentro de la esfera de su ordenamiento, en el núcleo de su representación o significación del texto legal.

El delito flagrante es lo opuesto a lo clandestino; y como tal, debe cometerse públicamente y ante testigos. Requiere que la víctima, la policía o un tercero presencien la comisión del delito en el mismo momento en que se perpetra (evidencia o percepción sensorial del hecho delictivo), y que ante la realización de la infracción penal surja la necesidad urgente de la detención del delincuente para poner coto a la comisión delictiva, cortar o evitar mayores efectos lesivos de la conducta delictiva o impedir la fuga del delincuente.

La inmediatez que ello implica hace patente el hecho delictivo - la flagrancia se ve, no se demuestra - y su comisión por el detenido, de suerte que como existe una percepción 
Revista Eletrônica de Direito Processual - REDP.

Rio de Janeiro. Ano 11. Volume 18. Número 2. Maio a Agosto de 2017

Periódico Quadrimestral da Pós-Graduação Stricto Sensu em Direito Processual da UERJ

Patrono: José Carlos Barbosa Moreira. ISSN 1982-7636. pp. 327-346

www.redp.uerj.br

directa y sensorial del delito, excluye de por sí de toda sospecha, conjetura, intuición o deducción. Se asume por ello que todos los elementos están presentes y que no cabe elaborar un proceso deductivo más o menos complejo para establecer la realidad del delito y la participación del detenido.

Se trata de la denominada "cuasi flagrancia". Por otro lado, ser testigo presencial del delito — verbigracia: víctima, policía, sereno u otra persona - importa que directamente y a través de sus sentidos expone acerca de lo que observó y esa observación está referida precisamente, a la comisión de un delito. No cumple con este requisito la institución del testigo de oídas o de referencia, pues solo puede mencionar lo que alguien le contó acerca de un suceso determinado: Su información es indirecta, la obtiene a través de manifestaciones o confidencias de terceras personas y al ser prueba indirecta, su información debe ser contrastada, por el testigo fuente que sería el presencial.

En el presente caso, los policías captores no presenciaron la comisión del delito. Tampoco lo hizo la madre, ni siquiera la tía de la niña. Ambas se limitaron a expresar lo que la niña, luego del suceso, les dijo, cuando ni siquiera el imputado se encontraba en la vivienda de aquella. Con independencia de lo que mencionó la niña agraviada y del valor probatorio que puede otorgársele a su testimonio, lo cierto que el delito sub judice no puede clasificarse como flagrante.

Un caso como el aludido requiere de un elaborado análisis deductivo, de un riguroso análisis de la versión de la víctima y de una actividad probatoria variada o diversa, tanto mas: i) si no se cuenta con vestigios materiales y fluidos corporales examinados pericialmente, ii) si la captura no se produjo en el mismo momento o instantes después de sucedido el hecho delictivo, esto es, a las 22 horas del día siguiente, y iii) si el imputado niega los cargos, e incluso está en la posibilidad de ofrecer, desde la perspectiva de un procedimiento más extenso, prueba documental y personal de descargo. 
Revista Eletrônica de Direito Processual - REDP.

Rio de Janeiro. Ano 11. Volume 18. Número 2. Maio a Agosto de 2017

Periódico Quadrimestral da Pós-Graduação Stricto Sensu em Direito Processual da UERJ

Patrono: José Carlos Barbosa Moreira. ISSN 1982-7636. pp. 327-346

www.redp.uerj.br

La violación sexual de menor de edad es un delito especialmente grave — está asociado a la pena más grave del sistema penal: cadena perpetua-, por lo que por razones de estricta proporcionalidad, no puede solventarse sin prueba evidente derivada de la flagrancia, en un proceso célere y de reducida acción probatoria, como el proceso inmediato.

Se desvió así, en el caso concreto, al imputado del procedimiento legalmente preestablecido, que es el común, derivándolo irrazonablemente al proceso inmediato, incurriéndose en nulidad absoluta e insubsanable. Ergo, no cabe saneamiento ni convalidación, pues no se trata de una mera inobservancia de las formalidades previstas en el Código, sino de una auténtica lesión al debido proceso legal.

La desestimación de la incoación del proceso inmediato no trae consigo necesariamente la anulación de la prisión preventiva y la modificación de esta medida requiere de una petición de parte, unida a un debate sobre los presupuestos materiales correspondientes.

Finalmente, la Primera Sala Penal Transitoria de la Corte Suprema declaró fundado el recurso de casación por quebrantamiento de precepto procesal interpuesto por la defensa del acusado, contra la sentencia de vista que confirmando la sentencia de primera instancia lo condenó como autor del delito de violación sexual de menor de edad, en agravio de M.B.A.A., a cadena perpetua. Nula la sentencia de vista recurrida e insubsistente la sentencia de primera instancia. Sin efecto todo lo actuado en esta causa desde el auto de incoación del proceso inmediato, sin perjuicio de la validez de la prueba documental, los informes o dictámenes periciales, las diligencias objetivas e irreproducibles y, en lo pertinente, de las actas que contienen las diligencias preliminares. Ordenó se siga la causa conforme al proceso común y se remitan los actuados a fiscalía provincial. Decretó la inmediata libertad del encausado por vencimiento del plazo de duración de la prisión preventiva.

\section{Análisis de la resolución in comento}


Revista Eletrônica de Direito Processual - REDP.

Rio de Janeiro. Ano 11. Volume 18. Número 2. Maio a Agosto de 2017

Periódico Quadrimestral da Pós-Graduação Stricto Sensu em Direito Processual da UERJ

Patrono: José Carlos Barbosa Moreira. ISSN 1982-7636. pp. 327-346

www.redp.uerj.br

La investigación, denuncia y sentencia de delito de violación sexual de menor de edad, comporta un cuidado sumo, en razón al bien jurídico tutelado, como a la pena máxima impuesta, esto es, cadena perpetua (como en efecto fue condenado el denunciado). Lo propio del proceso inmediato.

En ese sentido, respecto de la naturaleza del referido proceso, el segundo párrafo del fundamento jurídico 7, del Acuerdo Plenario Extraordinario N. o 02-2016/CIJ-116, señala:

Los presupuestos materiales o la naturaleza de su objeto: (i) de evidencia delictiva y (ii) de ausencia de complejidad y simplicidad, a los que se refiere el artículo 446, apartados 1) y 2), del NCPP (Decreto Legislativo 1194), de 30-08-2015), reclaman una interpretación estricta de las normas habilitadoras de este proceso especial, en cuanto el proceso inmediato, por ampararse en la simplificación procesal, reduce al mínimo indispensable -aunque no irrazonablemente - las garantías procesales de las partes, en especial las de defensa y tutela jurisdiccional de los imputados. Por consiguiente, en la medida que exista con claridad y rotundidad, prueba evidente o evidencia delictiva y simplicidad, la vía del proceso inmediato estará legitimada constitucionalmente.

Sin embargo, es de verse que la denunciante (madre de la menor), la policía y el fiscal provincial, no observaron los expresos alcances del referido plenario, y tampoco el contenido del artículo 446 del nuevo Código Procesal Penal - modificado por el artículo 2 del D. Leg. N. 1194, que regula el Proceso Inmediato en Casos de Flagrancia-, pues, en el segundo caso no se cumplía con ninguno de los supuestos de aplicación que refiere dicho artículo.

A todas luces, en el presente caso no se configuró una flagrancia delictiva. El problema se presenta cuando la fiscalía y el poder judicial intervinientes (excepto la Sala Suprema), asumen erróneamente que se trata de una cuasi flagrancia, aunque tampoco llegó a configurarse.

Al respecto, el profesor SÁNCHEZ VELARDE anota: 
Revista Eletrônica de Direito Processual - REDP.

Rio de Janeiro. Ano 11. Volume 18. Número 2. Maio a Agosto de 2017

Periódico Quadrimestral da Pós-Graduação Stricto Sensu em Direito Processual da UERJ

Patrono: José Carlos Barbosa Moreira. ISSN 1982-7636. pp. 327-346

www.redp.uerj.br

El Decreto Legislativo 1194 cambia el verbo rector "podrá" que facultaba al fiscal, por "deberá". Se afirma que ello afecta la discrecionalidad del fiscal. Ciertamente es discutible, pues en la práctica quien califica la flagrancia es el fiscal. Si dicha autoridad considera que los hechos no configuran flagrancia, no está obligado a requerir el proceso inmediato. Si existiendo flagrancia, el fiscal no cuenta con los elementos de prueba materiales inmediatos para sustentar su pedido ante el juez (por demora en las pesquisas, por ejemplo), deberá seguir con el proceso común 6 .

Sin embargo, parece ser que el fiscal no lo entendió así y optó por el proceso inmediato, cuando ello no lo ameritaba. A propósito, nos llama la atención que se haya configurado cual "piezas de dominó", por decir lo menos. Es decir, que hubo un yerro en cadena, en la actuación de la policía, la fiscalía y el poder judicial, en sus instancias a quo y ad quem. ¿Se equivoca uno y se equivocan también todos los demás? Menos mal que Corte Suprema supo evidenciar y corregir.

Amerita acotar la lamentable paradoja, en la que se incurrió al aplicar erróneamente la incoación del proceso inmediato en lugar del común, puesto que la fiscalía, al intentar salvaguardar el bien jurídico protegido de la menor presuntamente agraviada —esto es, su indemnidad sexual-, termina vulnerando peligrosamente no pocos derechos fundamentales del presunto culpable, como son los derechos: i) a la motivación de las resoluciones jurisdiccionales, ii) a no ser desviado de la jurisdicción determinada por ley — por la clamorosa equivocación de la incoación del proceso inmediato- - iii) a la libertad personal — por el arresto policial y la condena a cadena perpetua impuesta-, iv) al cuestionamiento de una decisión jurisdiccional — al haberlo impedido, arguyendo la aplicación del principio de convalidación por omisión-, y iv) al debido proceso penal. En suma, se incurrió en una abierta y sistemática vulneración de la legalidad, constitucionalidad y legitimidad en menoscabo del acusado.

6 SÁnchez Velarde, Pablo, “La flagrancia y el proceso inmediato", en El Comercio, Lima: 1 de febrero del 2016. Recuperado de <bit.ly/1Wx2BNI>. 
Revista Eletrônica de Direito Processual - REDP.

Rio de Janeiro. Ano 11. Volume 18. Número 2. Maio a Agosto de 2017

Periódico Quadrimestral da Pós-Graduação Stricto Sensu em Direito Processual da UERJ

Patrono: José Carlos Barbosa Moreira. ISSN 1982-7636. pp. 327-346

www.redp.uerj.br

En consecuencia, el caso materia de análisis es un claro y lamentable ejemplo de como el remedio termina siendo peor que la enfermedad. El Estado (PNP, Ministerio Público y Poder Judicial), no puede volverse contra su creador: el pueblo; no puede desconocer su razón de ser, esto es, estar al servicio y beneficio de la población (en justicia).

Más aún, analizando el caso concreto desde los predios de la administración pública (que engloba a la administración de justicia), tenemos que el funcionario público se encuentra obligado a generar valor público, porque el mismo labora con fondos públicos, los mismos que les pertenecen a la población y por ende tiene que estar orientados hacia ella en general y específicamente a los sectores más deprimidos, de otro modo, se posterga y desnaturaliza la finalidad que abraza la función pública ${ }^{7}$. Se colige pues, que en ningún caso su misión aterriza en ocasionar perjuicio alguno. Por ello, es que sostenemos que en el caso concreto no se ha tomado ni por asomo dichos postulados de la administración.

A propósito, el valor público constituye una obligación para quienes están a cargo de la gestión pública, porque los mismos laboran con fondos públicos, los que a su vez pertenecen a la población y por ende deben estar orientados hacia ella en general y específicamente a los sectores más deprimidos y no a otros fines, menos aún, cuando los referidos "otros fines", postergan y desnaturalizan la finalidad que abraza la función pública (sea generada vía elección popular o no). Así, el valor público busca de forma comprometida un sistema que promueva un desarrollo eficaz, eficiente, equitativo y sostenible. Bajo esta perspectiva, se busca la creación de valor público por medio de una gestión estatal, que contribuya significativamente a cuatro fines o principios fundamentales: i) la reducción de la desigualdad,

7 TORRES MANRIQUE, Jorge Isaac, “Breves notas a propósito de la reciente creación y puesta en marcha del plan piloto: 'Implementación de los órganos jurisdiccionales de flagrancia delictiva", en Revista de Estudios Jurídicos da Universidade Estadual Paulista Júlio de Mesquita Filho (UNESP), Brasil: 2015, p. 10. Recuperado de <bit.ly/2oKK4nc>. 
Revista Eletrônica de Direito Processual - REDP.

Rio de Janeiro. Ano 11. Volume 18. Número 2. Maio a Agosto de 2017

Periódico Quadrimestral da Pós-Graduação Stricto Sensu em Direito Processual da UERJ

Patrono: José Carlos Barbosa Moreira. ISSN 1982-7636. pp. 327-346

www.redp.uerj.br

ii) la reducción de la pobreza, iii) el fortalecimiento de estados democráticos, y iv) el fortalecimiento de la ciudadanía ${ }^{8}$.

A propósito, no poco se ha dicho respecto de la naturaleza y desarrollo del proceso inmediato contenido en el Código Procesal Penal, y lo propio de la flagrancia y cuasi flagrancia. Luego de casi tres lustros, parecería que no se tendría mayor inconveniente respecto del mismo por parte de los magistrados del Ministerio Público y del Poder Judicial. No obstante, no necesariamente es así.

Resulta lamentable que el denunciado haya sido privado injustamente de su libertad, a través de una prisión preventiva de catorce meses aproximadamente; deploramos que la Primera Sala Penal Transitoria de la Corte Suprema no se haya manifestado sobre la temeridad procesal en que incurrieron el fiscal provincial de la Primera Fiscalía Provincial Penal Corporativa de Sullana, el juez del Tercer Juzgado de Investigación Preparatoria de Sullana, así como, la Sala Superior que expidió la sentencia de vista. Desperdiciando así dicha Sala Suprema, la valiosa oportunidad de aterrizar en la ansiada como muchas veces esquiva justicia.

Mención aparte merece comentar la correcta aplicación retroactiva en sede penal que se aplicó al caso in comento. Ello en razón, a que si bien con fecha 20 de enero del 2016, el fiscal provincial de la Primera Fiscalía Provincial Penal Corporativa de Sullana, formuló el requerimiento de incoación de proceso inmediato; con fecha 16 de marzo del 2017, la Primera Sala Penal Transitoria de la Corte Suprema aplica los alcances contenidos por el Segundo Pleno Jurisdiccional Extraordinario de las Salas Penales Transitorias Permanente y Transitoria, acordado el 1 de junio del 2016. Esto es, luego de más de cinco meses.

Ahora bien, cabe mencionar que en anteriores trabajos no pocas veces hemos hecho especial mención a las resoluciones que pecan de ser legalistas, formalistas y sacrifican la

8 TORRES MANRIQUE, Jorge Isaac, "Nuevas maneras de generación de valor público en las contrataciones con el estado", en El terno no hace al abogado (portal web), S/F. Recuperado de <bit.ly/2oSXyiQ>. 
Revista Eletrônica de Direito Processual - REDP.

Rio de Janeiro. Ano 11. Volume 18. Número 2. Maio a Agosto de 2017

Periódico Quadrimestral da Pós-Graduação Stricto Sensu em Direito Processual da UERJ

Patrono: José Carlos Barbosa Moreira. ISSN 1982-7636. pp. 327-346

www.redp.uerj.br

justicia. Pero, en el presente caso va más allá aunque en sentido inverso, strictu sensu la sentencia de vista ni siquiera abrazó la legalidad al establecer el proceso inmediato cuando en realidad corresponde el común.

Al respecto, consideramos que incluso la Primera Sala Penal Transitoria de la Corte Suprema, que casó la sentencia ad quem, ciertamente se quedó corta, pues abrazó la legalidad y constitucionalidad, pero no la justeza. Dado que en el caso concreto no se justificó la incoación del proceso inmediato, entonces el juez de la causa en modo alguno debió acoger la prisión preventiva solicitada por la fiscalía.

En consecuencia, se equivoca la Corte Suprema al convalidar dicho oceánico error, al referir en el fundamento séptimo de la resolución bajo comentario que el referido Acuerdo Plenario estatuye que el fundamento jurídico de la desestimación de la incoación no trae consigo necesariamente la anulación preventiva, pues, requiere petición de parte, unida a un debate sobre los presupuestos materiales correspondientes. Extraviándose así, penosamente, en la ignominia dicho supremo colegiado en disquisiciones absolutamente prescindibles, cuando señala que el tiempo de privación procesal de la libertad es de nueve meses y que como ya alcanza los catorce meses y habiéndolo solicitado la defensa, entonces, procede la inmediata libertad del encausado.

En ese orden de ideas, consideramos que la Corte Suprema actuó correctamente, aunque de manera insuficiente al poner coto ante tanto yerro.

Así, ante tal decisión habría que cuestionar: ¿Cómo es que por un lado, dicha Sala Suprema rechaza el principio de convalidación por omisión del encausado y por otro, convalida los efectos del craso error de la fiscalía y Poder Judicial al decantarse estos últimos erradamente por el proceso inmediato en lugar del común? ¿Cómo es posible que dicho colegiado, ante el indebido padecimiento de privación de libertad por parte del encausado (incluso con condena a cadena perpetua), tenga que dilucidar sobre el tiempo de la misma y la 
Revista Eletrônica de Direito Processual - REDP.

Rio de Janeiro. Ano 11. Volume 18. Número 2. Maio a Agosto de 2017

Periódico Quadrimestral da Pós-Graduação Stricto Sensu em Direito Processual da UERJ

Patrono: José Carlos Barbosa Moreira. ISSN 1982-7636. pp. 327-346

www.redp.uerj.br

petición de parte, para la ordenar la variación de la prisión preventiva? ¿Y si la defensa no hubiese solicitado la anulación de la prisión preventiva, el injustamente condenado hubiera tenido que permanecer privado de su derecho a la libertad personal? ¿Esa es la finalidad y mística de la "justicia del siglo XXI", que basilarmente siempre piensa en todo, pero, casi nunca en el justiciable? ¿Esa es la “justicia” que se merece el justiciable? ¿Ello quiere decir, que si los magistrados se equivocan no les ocurre nada y más aún el acusado quien tiene que cargar injustamente con esa cruz? ¿En serio creen que la consabida como ansiada e histórica reforma del Poder Judicial (para sacar de la profunda crisis en que se encuentra sumida la administración de justicia), se hará solamente creando y construyendo más juzgados y designando más magistrados? ¿No será más bien un tema de calidad de magistrados, que de mera cantidad material como de indolentes como ajenos elefantes blancos?

En ese orden de pensamiento, en virtud del principio de legitimidad, sostenemos que el colegiado supremo bien pudo preferir la justicia en vez de sujetarse solo a la legalidad. El Acuerdo Plenario, definitivamente, no se aplica a este caso en mérito a que los presupuestos materiales han sido claramente desvirtuados. ¿Pretendían acaso someterse a un adicional debate para dilucidar lo ya dilucidado, esto es, que ameritaba la anulación de la prisión preventiva? Y es que al condenado no debió habérsele aplicado la pena en extremo alguno, ergo, lo justo era disponer su libertad ipso facto, sin que medie otra razón.

Prueba de ello, el artículo 7.3 de la Convención Americana de Derechos Humanos, respecto del derecho a la libertad personal, preconiza: "Nadie puede ser sometido a detención o encarcelamiento arbitrarios".

Si con ello no bastase, tenemos que los fundamentos 67 y 68, del caso López Álvarez vs. Honduras, sentencia de fecha 1 de febrero del 2006, emitida por la Corte Interamericana de Derechos Humanos, en relación a la arbitrariedad y prisión preventiva, respectivamente establece: 
Revista Eletrônica de Direito Processual - REDP.

Rio de Janeiro. Ano 11. Volume 18. Número 2. Maio a Agosto de 2017

Periódico Quadrimestral da Pós-Graduação Stricto Sensu em Direito Processual da UERJ

Patrono: José Carlos Barbosa Moreira. ISSN 1982-7636. pp. 327-346

www.redp.uerj.br

La prisión preventiva está limitada por los principios de legalidad, presunción de inocencia, necesidad y proporcionalidad, indispensables en una sociedad democrática. Constituye la medida más severa que se puede imponer al imputado, y por ello debe aplicarse excepcionalmente. La regla debe ser la libertad del procesado mientras se resuelve acerca de su responsabilidad penal.

$[\ldots]$

La legitimidad de la prisión preventiva no proviene solamente de que la ley permite aplicarla en ciertas hipótesis generales. La adopción de esa medida cautelar requiere un juicio de proporcionalidad entre aquélla, los elementos de convicción para dictarla y los hechos que se investigan. Si no hay proporcionalidad, la medida será arbitraria.

Finalmente, dejamos constancia de haber aplicado en el presente trabajo, los preceptos de la argumentación jurídica sistémica interdisciplinaria — de mi autoría —-, que consta de siete etapas o estadíos, a saber: i) la legalidad, ii) la constitucionalidad, iii) los precedentes vinculantes, iv) Las demás fuentes del derecho, v) convencionalidad, vi) multidisciplinariedad, y vii) legitimidad.

En ese sentido, se tiene que la resolución sub examine en perjuicio del presunto culpable, solo alcanza a ser legal y constitucional; incumpliendo con la obligada convencionalidad, multidisciplinariedad - en vista de la inobservancia de los indicados principios de la administración_-, y la legitimidad o justicia. Incurriendo así, en prevaricato la fiscalía y el Poder Judicial por no haber acatado la inconvencionalidad.

En suma, al justiciable se le ofreció una supuesta justicia legal — ajustada a lo previsto en la ley_, una justicia constitucional — que engloba lo preconizado en la Constitución Política-; pero no en términos de justeza, legitimidad o justicia propiamente dicha, pues la justicia es una sola.

9 Véase, ToRres MANRIQue, Jorge Isaac, “Argumentando de manera jurídica sistémica e interdisciplinaria”, en El terno no hace al abogado (portal web), S/F. Recuperado de 〈bit.ly/2oJnCwp>. 
Revista Eletrônica de Direito Processual - REDP.

Rio de Janeiro. Ano 11. Volume 18. Número 2. Maio a Agosto de 2017

Periódico Quadrimestral da Pós-Graduação Stricto Sensu em Direito Processual da UERJ

Patrono: José Carlos Barbosa Moreira. ISSN 1982-7636. pp. 327-346

www.redp.uerj.br

\section{Conclusiones}

La resolución bajo comentario refleja varias deficiencias. Solo logró decantarse por la legalidad y constitucionalidad, dejando de lado, la convencionalidad, multidisciplinariedad y justeza. Aunque, increíblemente constituye un avance en dicha sede, acostumbrada a abrazar únicamente la legalidad; queda pendiente un largo y necesario camino de evolución de la administración de justicia. Ello debe llamar a una profunda reflexión y enmienda.

El solo hecho de haber incurrido (y convalidado) en el error en cadena, tanto la policía, la fiscalía y el Poder Judicial, refleja de manera irrefutable como penosa, el estado que la administración de justicia nos puede "regalar" en cualquier momento.

\section{Sugerencias}

- La capacitación y concientización en temas de administración de justicia se tornan muy urgentes como insoslayables, en razón a que en las situaciones extremas, como los delitos de mayor gravedad — verbi gratia, el delito de violación sexual de menor de edad—, se requiere a fortiori de mayor cuidado — más aun, cuando la cuasi flagrancia se adiciona-. Ello, en tanto que se decide nada menos que la cadena perpetua para el sujeto activo. Ahí es cuando el preciado bien jurídico de la libertad — solo postergado por el bien jurídico vida—, refleja su gran trascendencia como cuidado sumo.

- Postulamos que la administración de justicia se decanten por la justeza, legitimidad, en desmedro de la ligereza e insuficiente rigor jurídico con que ha manejado el presente caso.

- En las resoluciones judiciales es necesario abordar el fundamento jurídico, también a la luz de la convencionalidad y multidisciplinariedad. 
Revista Eletrônica de Direito Processual - REDP.

Rio de Janeiro. Ano 11. Volume 18. Número 2. Maio a Agosto de 2017

Periódico Quadrimestral da Pós-Graduação Stricto Sensu em Direito Processual da UERJ

Patrono: José Carlos Barbosa Moreira. ISSN 1982-7636. pp. 327-346

www.redp.uerj.br

\section{REFERENCIAS BIBLIOGRÁFICAS:}

Araya Vega, Alfredo. "El nuevo proceso inmediato (Decreto 1194). Hacia un modelo de una justicia como servicio público de calidad con rostro humano", en Revista Informativa Ius Infraganti, año 1, n. ${ }^{\circ}$ 1, Lima: marzo del 2016, pp. 6-12. Recuperado de <bit.ly/1RCay0p〉.

SÁncheZ Velarde, Pablo, "La flagrancia y el proceso inmediato", en El Comercio, Lima: 1 de febrero del 2016. Recuperado de <bit.ly/1Wx2BNI>.

TORRES MANRIQUE, Jorge Isaac, "Argumentando de manera jurídica sistémica e interdisciplinaria", en El terno no hace al abogado (portal web), S/F. Recuperado de $<$ bit.ly/2oJnCwp>.

TORRES MANRIQUE, Jorge Isaac, "Breves notas a propósito de la reciente creación y puesta en marcha del plan piloto: 'Implementación de los órganos jurisdiccionales de flagrancia delictiva'", en Revista de Estudios Jurídicos da Universidade Estadual Paulista Júlio de Mesquita Filho (UNESP), Brasil: 2015. Recuperado de <bit.ly/2oKK4nc〉.

TORRES MANRIQUE, Jorge Isaac, "Nuevas maneras de generación de valor público en las contrataciones con el estado", en El terno no hace al abogado (portal web), S/F. Recuperado de <bit.ly/2oSXyiQ>. 